\title{
A GLIMPSE INTO MY WORLD OF DESIGNING
}

\author{
Rekha R. Shailaj
}

As a fashion design practitioner, I mostly engage in the hands-on, immersive act of making. However, it is through the creative written expression of my practice that I can give my work a measurable, tangible form and visibility. In this writing I answer the questions: What is my practice, how do I advance it, what meanings do I assign to it, and where and how do I locate it?

Creativity is omnipresent in my life, residing in the apparatus of my hands, mind, senses, tools, materials and memories. The critical impetus for my process of designing is a strong motivation to translate creative ideas into physical forms. For each design, the direct connection between thinking, ideating and making physicality, with my synchronous action of hands, mind, tools and materials, is my creative journey. My approach to designing mirrors that of Leslie Hirst, who is captivated by the transformation of materials by human hands. Her experiences enable her to see something more than the surface when looking directly at any image, object or event (Hirst, 20 I 3):

As a researcher, I am aware that my focus is not so much on the methods I use, but rather on the transformative nature of my design process which is informed by social reality. Hence, I find that I often need to work with a variety of research methods including reflexive, reflective, narrative/storytelling, interpretive/contextual, and iterative action approaches (Shailaj, 2019).

Joe Kincheloe and Kathleen Berry acknowledge the power of bricolage in their research methods and elaborate on the bricoleur's research position as one who interacts with the objects of their inquiry in a complicated, unpredictable and complex way (Kincheloe \& Berry, 2004, pp. I-3). As a bricoleur, I actively construct my research methods from the 'objects' at hand, engaging with my social reality and developing personal forms of research processes and narratives.

I ideate design through draping fabric on a body form, exploring the geometries of shape and form. Drape provides a way for me to sketch designs on a body form. I choose to work and sculpt with diverse materials, from cardboard boxes to fabric, shaping them with my hands.

Figure I. Rekha R. Shailaj, cardboard dress, 2016.

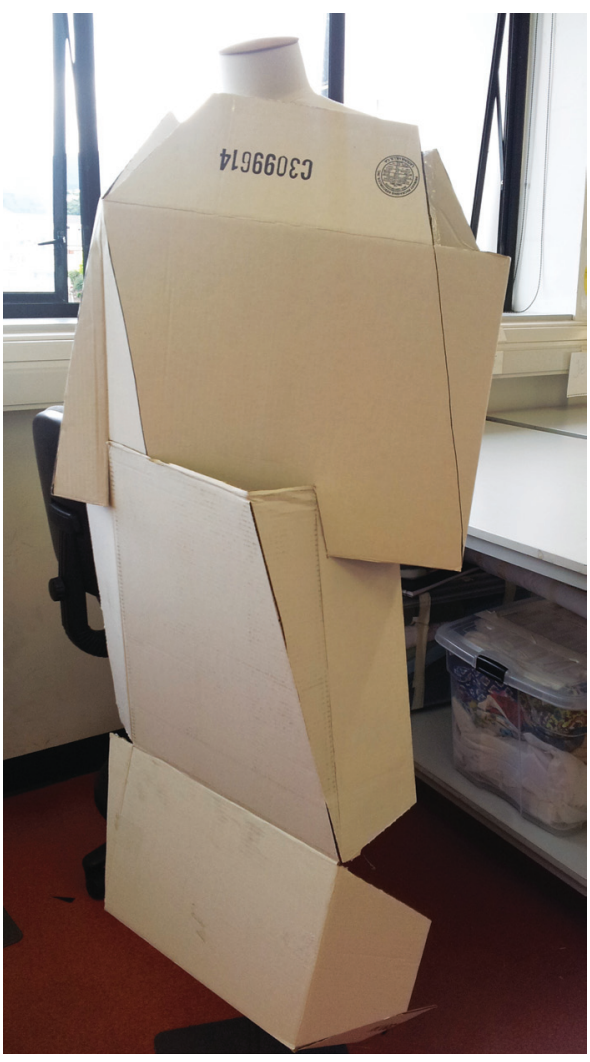




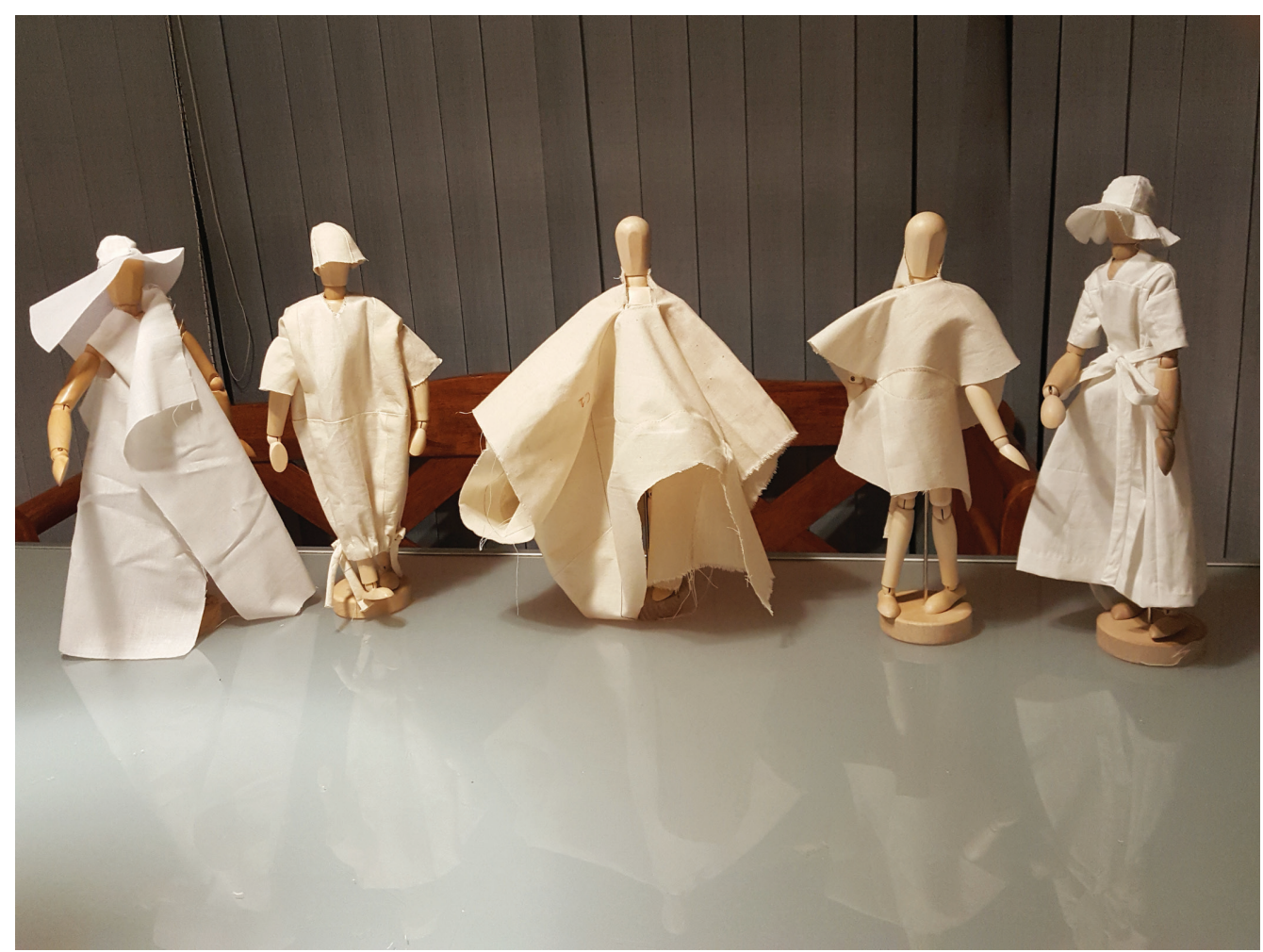

Figure 2. Design ideation with zero-waste techniques, 202I.

As my process unfolds, new designs with unconventional silhouettes take shape. Handson exploration and experimentation with materials are a key element of my design process. I seek to displace seams around the body and generate alternative garment forms. This approach echos Madeleine Vionnet's masterly practice of draping fabric in a way that transforms two-dimensional fabric into threedimensional forms (Vinken, 2005, p. I I I).

Creative ideas surface during the early morning sleep hours when I am in a subconscious state

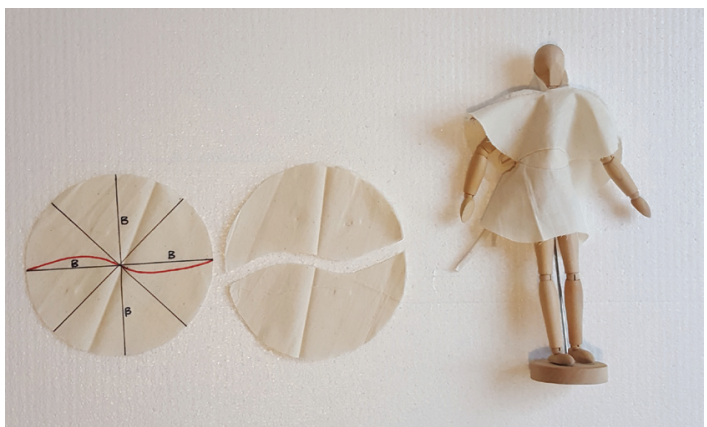

Figure 3. Design ideation using quarter-size mannequins, 2021. or when exercising on a treadmill. I then make time to explore those ideas formed by my subconscious mind. I draw upon my personal cultural inventory, ethnographic garments from India, as a significant inspiration. "When I engage in fashion design, my work is generally informed by nostalgia for my motherland and its traditional clothing, textiles, and techniques" (Shailaj, 2019, p. 47).

I collect in order to study in detail traditional clothing from India. Analyzing each item as an artifact, I study motifs, scale, colour, material, style and techniques. Sarah Ganz Blythe suggests that "objects can operate as pedagogical 


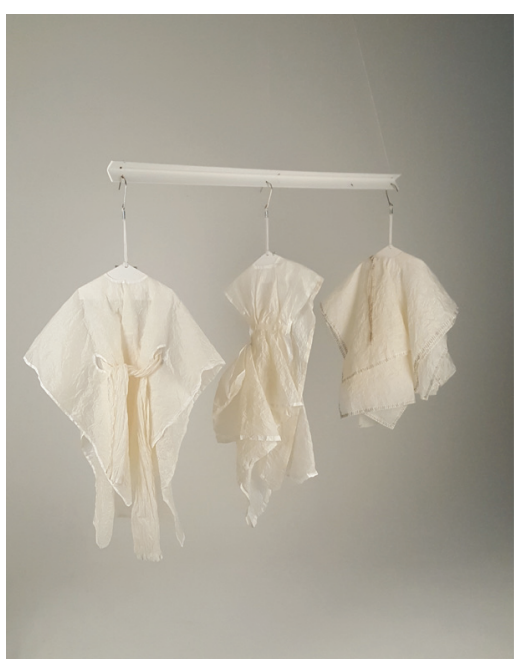

Figure 4. Recording the design process through prototyping and a visual diary.

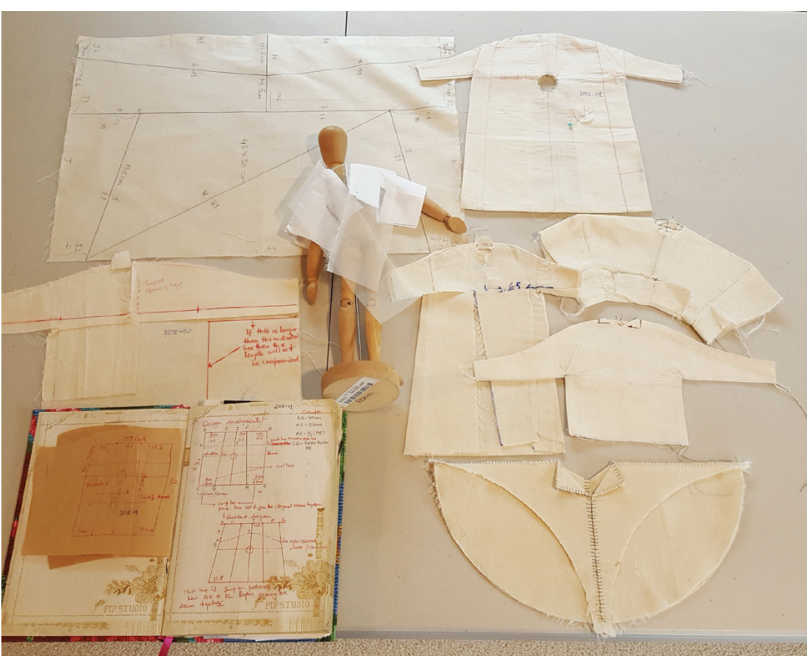

Figure 5. Design ideation with swapping, rotating and shaping for new silhouettes.

models, or tools" and that "through close looking, careful investigation, and thoughtful reflection, objects from varied cultures and contexts invite us to encounter complex social and cultural narratives, to draw upon personal knowledge and experience, and to imagine multivalent ideas and meanings - to let curiosity about the existing lead to the production of the new" (Blythe, 20 I3). These are the research approaches I recognise in my own process.

For inspiration, personal and treasured archives of my own past designs and experiences are valuable. My design forms are my expressions of lived experiences. MaxVan Manen correlates

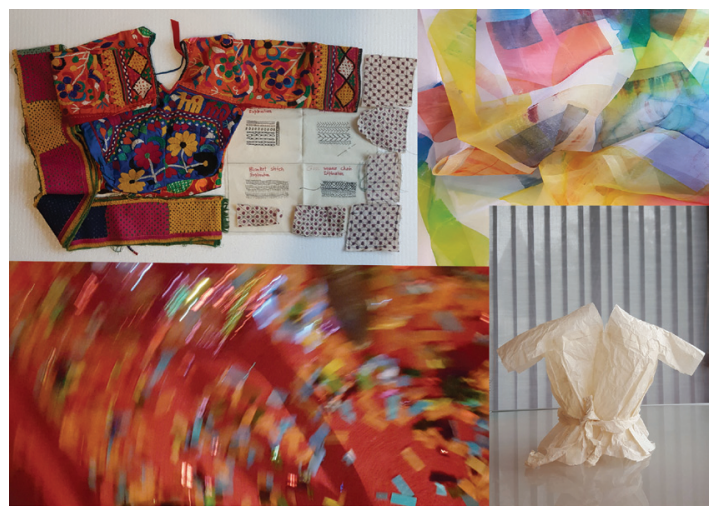

Figure 6. Rekha R. Shailaj, works inspired by the kurta. artists' creative expression with their lived experiences, so that they become transcended configurations (Van Manen, 20I5). The kurta is just such a significant piece of clothing from India, that I re-interpret frequently when designing.

My design process is a cyclical process of researching, making, testing and reflecting. My logical mind seeks to know each sequential step as if in the mindful calculation of a mathematical 'equation.' Yet in a creative 'equation', I introduce unusual variables that create a jumbled path towards my design solutions. Some of these variables, as observed in Maya Lin's practice (Lin, 2000), are intuitive gestures, connections, relationships to people and the environment, technology, and a 'Thirdspace' somewhere between East and West. My non-linear design process has both method and chaos occurring together. This aligns with John Dunningan's explanation of design as "a nonlinear and open-ended creative process, integrating conceptual, intuitive, sensory, technical, and contextual components" (Dunnigan, 20I3). When designing, I dwell on the unpredictability and complex journey which leads to unique outcomes. I systematically record all design iterations through workbook practice and half- or quarter-scaled design prototypes, providing a foundation for future replication. 
One key design aim is to appreciate and conserve material resources. I am committed to exploring near zero-waste design methods of cutting and constructing with fabric. These experiments are shown in the images from my workbook reproduced here (Figure 7). As is evident in these designs, the geometric shapes I utilise lend themselves to the goal of near zero-waste design iterations.

While I am designing, the wearer is always at the centre of my design considerations. The phenomenological engagement of the wearer with the clothes is paramount in all design decisions. I carefully consider the space between the garment and the body as I explore. This appreciation for the space between the body and garment is informed by Yamamoto's design engagement between the body and garment, through which he explores "Ya,"' a remarkable feeling of space," as Barbara Vinken explains (Vinken, 2005, p. III).

Design ideation is, for me, the most interesting part of designing, requiring only minimum resources - paper, scissors, pencil and a grading ruler. Ideation is augmented

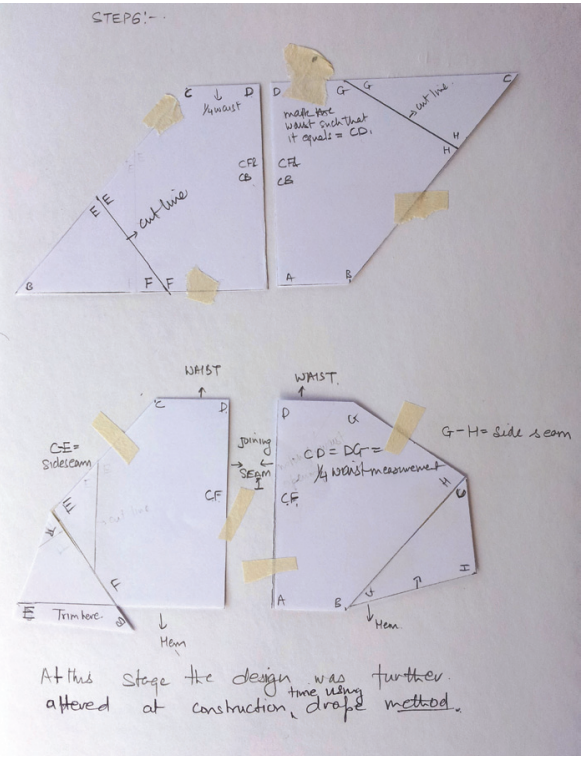

Figure 7. Designs exploring the space between the garment and the body. with my knowledge of geometry, form, shape and structure. I formulate designs through acts of deconstructing, collaging, shifting and otherwise manipulating geometric shapes to arrive at new forms that differ from current conventional forms. I explore using a range of pattern-cutting and construction techniques. It is through this combined approach to 'making', together with ongoing reflection, that my designing becomes a constructive, critical and immersive process.

My practice is informed by contemporary processes, other designers, practitioners and scholars who are innovating in the area of zero-waste fashion design methods and systems. Dr Mark Liu has forged a unique aesthetic for zero-waste garments and explored many new zero-waste patternmaking techniques. Mathematics and geometry underpin my design work as I explore zero-waste design innovations. While my designs are mostly governed by standard geometric rectangular/square shapes, these are transformed into new shapes using geometric concepts, applied mathematical interventions, shape and the space of and around the body. These designs result in a variety of forms and silhouettes.

To conclude, design is vital to feed my creative expression and indeed my very existence. Hence I am driven to make sense of design and designed outcomes. Klaus Krippendorff asserts that "making sense always entails a bit of a paradox between the aim of making something new and different from what was there before, and the desire to have it make sense, to be recognizable and understandable. The former calls for innovation, while the latter calls for the reproduction of historical continuities" (Krippendorff, 1995, p. I56). In my design practice, this making sense is contextualised through my reality of cultural difference, part of my experience and expression. It is through the universal language of design that I can make sense of my design world placed within the external world. 
Rekha Rana Shailaj is a Senior Lecturer at School of Design, Otago Polytechnic teaching on the Fashion program. Rekha holds a Diploma in Design (Fashion) and a Master of Fine Arts (Design) with distinction. Rekha designs in a multicultural space, drawing on both Eastern and Western sensibilities. Her current research focus is on working with traditional clothing from India and extending the construction methods to create near zero-waste fashion outcomes.

\section{REFERENCES}

Blythe, S. G. (20 I3). Object lessons. In R. Somerson and M. L. Hermano (Eds.), The art of critical making: Rhode Island School of Design on creative practice (pp. I |6-137). John Wiley \& Sons.

Dunnigan, J. (20 I3). Thingking. In In R. Somerson and M. L. Hermano (Eds.), The art of critical making: Rhode Island School of Design on creative practice (pp. 94-I I5). John Wiley \& Sons.

Hirst, L. (20I3). Groundwork. In R. Somerson and M. L. Hermano (Eds.), The art of critical making: Rhode Island School of Design on creative practice (pp. 32-5I). John Wiley \& Sons.

Kincheloe, J. L., \& Berry, K. S. (2004). Rigour and complexity in educational research: Conceptualizing the bricolage. Open University Press.

Krippendorff, K. (1995). On the essential contexts of artifacts or on the proposition that 'design is making sense (of things)'. In V. Margolin \& R. Buchanan (Eds.), The idea of design: A design issues reader (pp. I56- I 84). The MIT Press.

Lin, M. (2000). Boundaries. Simon \& Schuster.

Shailaj, R. R. (2019). Different shades of life: A pedagogy of lived experiences. Scope: Art \& Design, 17, 4I-55.

Van Manen, M. (20I5). Researching lived experience: Human science for an action sensitive pedagogy. Routledge.

Vinken, B. (2005). Fashion zeitgeist:Trends and cycles in the fashion system. Berg. 